\title{
PENERAPAN TEKNOLOGI KOMPOS TAKAKURA BAGI MASYARAKAT DESA TANJUNG TERDANA KECAMATAN PONDOK KUBANG BENGKULU TENGAH SEBAGAI UPAYA PEMBERDAYAAN MASYARAKAT SADAR LINGKUNGAN
}

\section{IMPLEMENTATION OF TAKAKURA COMPOSTING FOR FARMERS IN TANJUNG TERDANA VILLAGE PONDOK KUBANG BENGKULU TENGAH, AS AN EFFORT TO EMPOWER ENVIRONMENTALLY CONCIOUS COMMUNITY}

\author{
Oleh: \\ Dewi Jumiarni \\ Universitas Bengkulu \\ dewij@unib.ac.id \\ Rendi Zulni Eka Putri \\ Universitas Bengkulu \\ rendizulni.ekaputri@yahoo.co.id \\ Nike Anggraini \\ Universitas Sriwijaya \\ anggraini.nike@pps.unsri.ac.id
}

\begin{abstract}
ABSTRAK
Permasalahan yang dihadapi warga masyarakat Desa Tanjung Terdana adalah kondisi perekonomian masyarakat yang rendah, yaitu hanya mengandalkan penghasilan dari bertani, dan masyarakat belum memiliki keterampilan teknologi tepat guna sederhana yang memadai. Kegiatan pengabdian pada masyarakat ini bertujuan untuk : 1) Meningkatkan pengetahuan masyarakat dalam pengelolaan sampah organik rumah tangga menggunakan teknologi kompos Takakura sebagai salah satu potensi sumber industri rumah tangga untuk menambah penghasilan masyarakat, 2) Meningkatkan keterampilan bagi masyarakat dalam memanfaatkan teknologi kompos Takakura sebagai salah satu cara untuk meningkatan keterampilan dan perubahan pola pikir masyarakat sadar lingkungan. Metode kegiatan yang diberikan meliputi pelatihan, pengerjaan tugas terbimbing, dan monitoring serta evaluasi. Kegiatan dilaksanakan pada 4 Agustus 2018 di rumah kepala desa Tanjung Terdana. Kegiatan ini telah meningkatkan pengetahuan dan skill masyarakat Desa Tanjung Terdana dalam pengelolaan sampah rumah tangga menggunakan teknologi sederhana pembuatan kompos Takakura.
\end{abstract}

Keywords: pengomposan takakura, sampah organik, kompos

\begin{abstract}
The problem faced by farmers of Tanjung Terdana Village is the lower economical condition, which is income only from farming, and the society does not yet have adequate simple technology skills. The Community Engagement activities aims : 1) to increase knowledge in household organic waste management using Takakura compost technology as a potential bussiness of household industry to increase society income, 2) to improve skills of society in utilizing Takakura composting technology as one way to improve skills and change mindset of environmentally consciouss society.
\end{abstract}


The method of activities provided includes training, guided assignment work, and monitoring and evaluation. The activity was held on August 4, 2018 at the house of Tanjung Terdana village headman. This activity has increased the knowledge and skills of Tanjung Terdana Village community in household waste management using a simple technology of Takakura composting.

Keywords: Takakura composting, organic waste, compost

\section{PENDAHULUAN}

Desa Tanjung Terdana terletak di Kecamatan Pondok Kubang, Kabupaten Bengkulu Tengah, Provinsi Bengkulu. Potensi fisik Desa Tanjung Terdana masih tergolong baik dan alami, karena pengolahan yang dilakukan masih sangat sederhana dan tradisional. Masyarakat hanya menggantungkan kehidupannya dengan bercocok tanam tanaman padi sebagai mata pencaharian, sehingga ketika musim kemarau atau pada saat bendungan air dalam proses perbaikan kebanyakan masyarakat desa tinggal di rumah tidak mengolah lahan persawahannya atau cenderung mengganggur. Hal ini menyebabkan kondisi perekonomian masyarakat desa Tanjung Terdana berada pada tingkat ekonomi ke bawah. Di desa ini belum terlihat adanya kegiatan industri rumah tangga yang dapat meningkatkan pendapatan penduduk.

Mayoritas masyarakat Desa Tanjung Terdana lulusan Sekolah Lanjutan Tingkat Atas dan Sekolah Dasar. Hal ini menyebabkan masyarakat belum memiliki keterampilan teknologi tepat guna yang memadai. Pelatihan keterampilan dan peningkatan pemahaman masyarakat sebagai upaya peningkatan pemberdayaan masyarakat menjadi penting di Desa Tanjung Terdana agar mampu menunjang dan mengarahkan perilaku dan pola pikir masyarakat menjadi produktif. Peningkatan dan perubahan pola pikir masyarakat dapat dilakukan dengan adanya dorongan dari pihak luar untuk meningkatkan skill dan soft skill masyarakat diberbagai bidang salah satunya bidang teknologi. Salah satunya yaitu dengan memanfaatkan alam dan sumber daya alam menjadi suatu produk bernilai ekonomis dan bermanfaat besar. Sumber daya alam berupa tumbuhan dan hewan dapat dijadikan sebagai produk berteknologi sederhana, misalnya pengelolaan sampah.

Pelestarian, perlindungan dan pengeloaan lingkungan hidup dalam upaya mendukung pembangunan berkelanjutan dapat dilakukan melalui pemanfaatan lingkungan hidup untuk menghasilkan produk / bahan organik yang berasal dari limbah pertanian dan peternakan. Hal ini dapat dilakukan dengan pemanfaatan limbah pertanian, limbah perternakan dan limbah rumah tangga yang melimpah disekitar lingkungan kita menjadi suatu produk organik yang bernilai ekonomis dan praktis. Penggunaan bahan-bahan organik juga dapat meningkatan kualitas hidup manusia yang seimbang dengan alam serta berjalan secara lestari dan berkesinambungan melalui teknologi pengelolaan sampah organik.

Teknik pengelolaan organik merupakan bentuk daur ulang hara tanaman secara alami untuk meningkatkan kesuburan biologis, fisik, dan kimia tanah. Hara makro dan mikro yang terangkut panen dikembalikan dengan menambahkan pupuk organik dan sisa tanaman secara periodik ke dalam 
tanah, baik dalam bentuk pupuk hijau maupun kompos. Pupuk organik dianjurkan berasal dari bahanbahan organik seperti kotoran ternak yang dikomposkan, serasah sisa tanaman legum, pangkasan tanaman pagar, sampah organik, dan hijauan titonia.

Pupuk organik padat berupa pupuk kompos adalah bahan-bahan organik yang telah mengalami pelapukan karena adanya interaksi antara mikroorganisme yang bekerja didalamnya.Bahan-bahan organik tersebut seperti dedaunan, kotoran hewan, jerami padi, dan lain-lain. Penggunaan kompos sebagai pupuk sangat baik karena dapat memberikan manfaat yaitu menyediakan unsur hara mikro bagi tanaman, menggemburkan tanah, memperbaiki struktur dan tekstur tanah, dapat meningkatkan daya ikat tanah terhadap air, memudahkan pertumbuhan akar tanamam, menyimpan air tanah lebih lama, mencegah lapisan kering pada tanah dan mencegah beberapa penyakit akar, menghemat pemakaian pupuk kimia atau pupuk buatan, bersifat multiguna karena bisa dimanfaatkan untuk bahan dasar pupuk organik yang diperkaya dengan mineral, inokulum bakteri pengikat nitrogen (Murbandono, 2008).

Pengomposan Takakura disebut juga Takakura Home Method Composting, merupakan metode pembuatan kompos untuk mendaur ulang sampah dapur. Metode ini pertama kali diperkenalkan di Surabaya pada tahun 2004 oleh seorang berkebangsaan Jepang bernama Mr. Takakura. Metode pengomposan Takakura memiliki keunggulan dibandingkan dengan metode pengomposan lain, yaitu : 1. Praktis karena sangat cocok untuk perumahan dengan lahan yang tidak begitu lebar. Keranjang dapat ditempatkan di mana saja sesuai dengan kebutuhan dan ketersediaan lahan. 2. Mudah karena sampah hanya dimasukkan, setiap harinya. Tanpa ada perlakukan khusus seperti menambahkan cairan atau bahan-bahan tambahan yang lain. 3. Tidak berbau karena prosesnya melalui proses fermentasi, bukan pembusukan. Studi optimasi pengomposan Takakura dengan penambahan sekam dan bekatul menunjukkan hasil bahwa kandungan Karbon, Nitrogen, Phospor, dan Rasio C/N keseluruhan kompos matang telah memenuhi standar dalam SNI 19-7030-2004, standar internasional, dan Departemen Pertanian, tetapi masih belum sesuai dengan standar Departemen Pertanian dan PT. PUSRI (Rezagama dan Samudro, 2015).

Kegiatan pengabdian pada masyarakat ini dilakukan bertujuan untuk : 1) meningkatkan pengetahuan warga Desa Tanjung Terdana, Kabupaten Bengkulu Tengah dalam pengelolaan sampah organik rumah tangga menggunakan teknologi kompos Takakura sebagai salah satu potensi sumber industri rumah tangga untuk menambah penghasilan masyarakat, 2) Memberikan keterampilan bagi warga Desa Tanjung Terdana, Kabupaten Bengkulu Tengah dalam memanfaatkan teknologi kompos Takakura sebagai salah satu cara untuk meningkatan keterampilan dan perubahan pola pikir masyarakat sadar lingkungan. 


\section{METODE PENGABDIAN}

Kegiatan pengabdian pada masyarakat ini dilaksanakan di Desa Tanjung Terdana dengan khalayak peserta sebanyak 20 orang yang merupakan ibu rumah tangga. Metode kegiatan yang diberikan meliputi 4 tahap kegiatan yaitu persiapan, penyampaian materi, praktek terbimbing, monitoring dan evaluasi. Alat-alat yang digunakan untuk kegiatan ini adalah : keranjang pakaian, bantal sekam, kardus bekas, kain penutup dan pisau. Bahan-bahan yang diguanakan adalah sekam, dedak, tanah subur, gula, yogurt dan sampah organik rumah tangga.

\section{HASIL DAN PEMBAHASAN}

Proses penguraian sampah organik menjadi kompos melibatkan aktivitas mikrorganisme dekomposer. Oleh karena itu perlu diciptakan kondisi lingkungan yang sesuai agar mikroorganisme dekomposer dapat bekerja secara optimal. Beberapa faktor yang mempengaruhi proses pengomposan yaitu ukuran partikel, aerasi, rasio $\mathrm{C}: \mathrm{N}$, porositas, kelembaban, temperatur, $\mathrm{pH}$, kandungan (Murbandono, 2007).

\section{A. Tahap Persiapan}

Pada tahap persiapan dilakukan pembuatan komposter dan pembuatan dekomposer. Komposter Takakura didesain dengan menggunakan keranjang berlubang (keranjang pakaian), kardus bekas, bantal sekam, kardus bekas, kain dan tutup keranjang. Alat dan bahan ini kemudian disusun berlapis membentuk komposter Takakura seperti pada Gambar 1. Penggunaan keranjang berlubang sebagai komposter dilakukan untuk memperlancar sirkulasi udara karena pengomposan Takakura terjadi secara aerob. Jika oksigen tidak tersedia, maka proses dekomposisi akan berlangsung secara anaerob, yang akan menghasilkan bau yang tidak sedap.

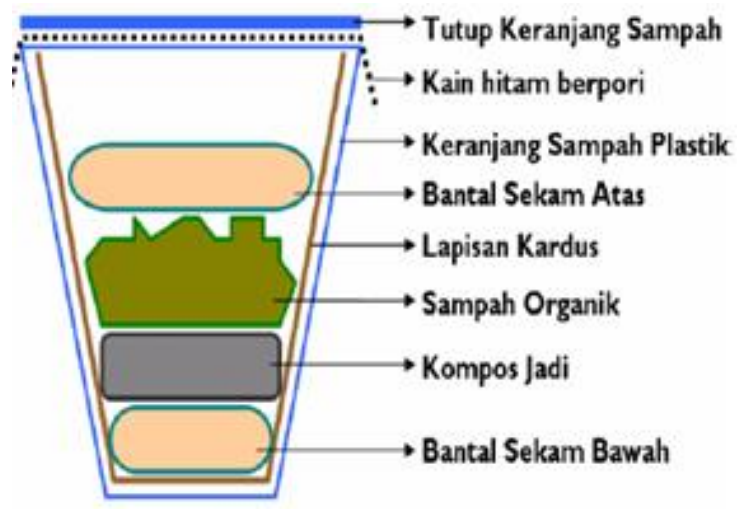

Gambar 1. Urutan susunan komposter (Sumunar et al., 2008)

Dekomposer / aktivator untuk pembuatan kompos Takakura ini diperoleh dari mikrorganisme lokal dalam tanah subur yang dipicu pertumbuhannya dengan penambahan bahanbahan lain seperti gula, sekam, dedak dan air. Gula pasir berperan sebagai sumber energi untuk 
pertumbuhan mikroorganisme. Air berperan untuk pertumbuhan mikroorganisme dan menjaga kelembaban kompos. Dedak berperan untuk mengurangi kelebihan air.

Pembuatan dekomposer dilakukan dengan cara mencampurkan dedak : sekam : tanah subur ( $1: 4: 3$ ) dengan air gula (100 gr gula dalam $250 \mathrm{ml}$ air), lalu ditambahkan air sedikit demi sedikit hingga campuran menjadi lembab dan dapat dikepal dengan tangan. Kelembaban yang tepat akan mempengaruhi keberhasilan proses pengomposan. Menurut Setyorini et al (2006), timbunan kompos harus selalu lembab (50-60\%) agar mikroorganisme tetap beraktivitas. Kelebihan air akan mengakibatkan volume udara jadi berkurang, sebaliknya bila terlalu kering proses dekompsisi akan terhenti. Setelah itu campuran dimasukkan ke dalam karung dan diinkubasi selama 1 minggu. Setelah 1 minggu aktivator yang telah diinkubasi telah siap untuk digunakan. Hal ini ditunjukkan dengan temperatur campuran yang terasa hangat dan tekstur yang lebih halus dari sebelumnya. Perubahan temperatur ini menandakan adanya aktivitas mikroorganisme yang sedang bekerja. Mikroorganisme ini yang akan membantu mempercepat proses pengomposan.
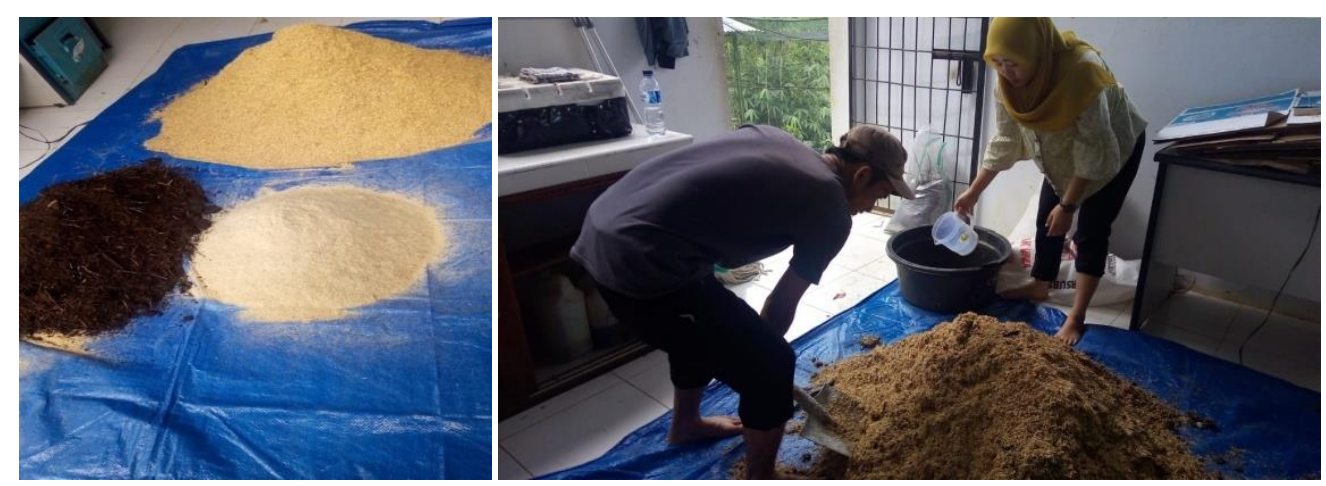

Gambar 2. Proses pembuatan dekomposer

B. Penyampaian Materi

Kegiatan pelatihan dan workshop dilaksanakan di rumah Kepala Desa Tanjung Terdana dihadiri 20 orang peserta yang terdiri dari ibu rumah tangga. Pada tahap ini dilakukan penyampaian materi mengenai pupuk organik, manfaat pupuk organik, dan proses pembuatan kompos takakura (Gambar 3). Setelah penyampaian materi dilakukan sesi tanya jawab. Peserta mengikuti antusias penyampaian materi dan banyak mengajukan pertanyaan. Peserta merasa tertarik dengan kegiatan ini karena pembuatan kompos metode Takakura baru pertama kali didengar. Selama ini peserta mengetahui pembuatan kompos dengan metode penimbunan dan pembakaran. Masyarakat menilai bahwa pembuatan kompos Takakura sangat sederhana dan mudah. Selain itu dengan pembuatan kompos Takakura, sampah rumah tangga yang selama ini menjadi limbah dapat dimanfaatkan. 

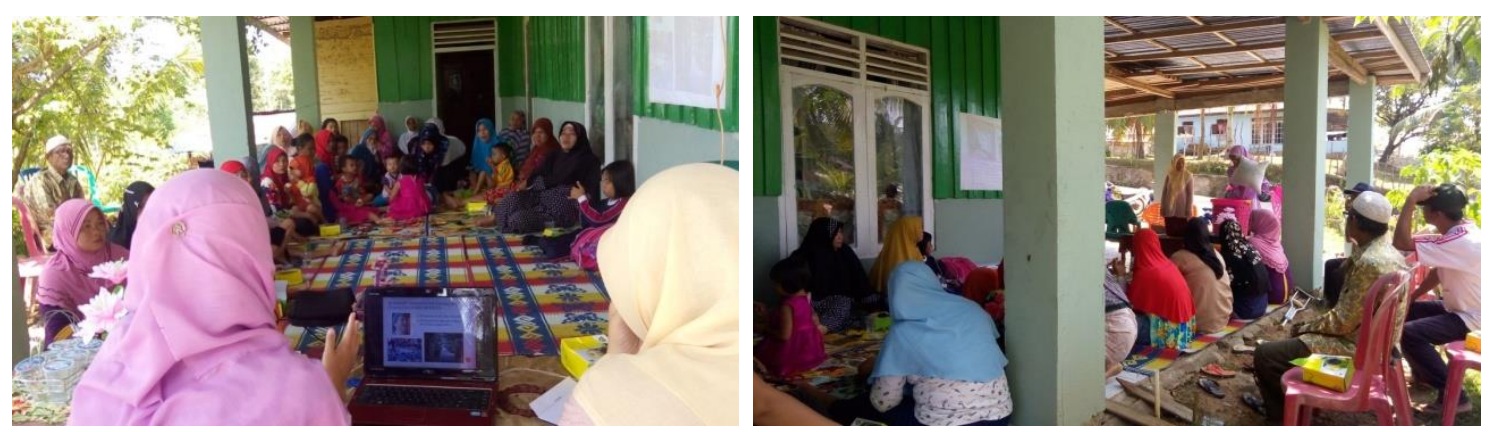

Gambar 3. Peserta mendengarkan penyampaian materi

\section{Praktek Terbimbing}

Pada tahap ini peserta mempraktekkan langsung pembuatan kompos takakura dengan bimbingan dari tim pengabdian. Kegiatan diawali dengan penyusunan komposter sesuai dengan urutannya (Gambar 4) dan dilanjutkan dengan memotong-motong dan memasukkan sampah sayuran ke dalam komposter. Pemotongan sampah sayuran dilakukan untuk mempercepat proses pengomposan. Seperti yang dinyatakan Setyorini et al. (2006) bahwa sampai batas tertentu, semakin kecil ukuran potongan bahan mentahnya, semakin cepat pula waktu pembusukannya. Namun ukuran potongan yang terlalu kecil akan mengakibatkan hilangnya difusi oksigen sehingga menyebabkan terjadi aktivitas bakteri anaerob (Suriawiria, 2002). Ukuran bahan sekitar 5-10 cm sesuai untuk pengomposan ditinjau dari aspek sirkulasi udara yang mungkin terjadi (Setyorini $e t$ al., 2006).

Peserta tidak mengalami kesulitan dalam praktek karena telah memahami dari penyampaian materi sebelumnya. Komposter yang telah diisi dengan sampah sayuran selanjutnya dibawa pulang oleh peserta untuk diinkubasi dan diisi sampah rumah tangga setiap hari hingga penuh (sekitar 1 bulan).
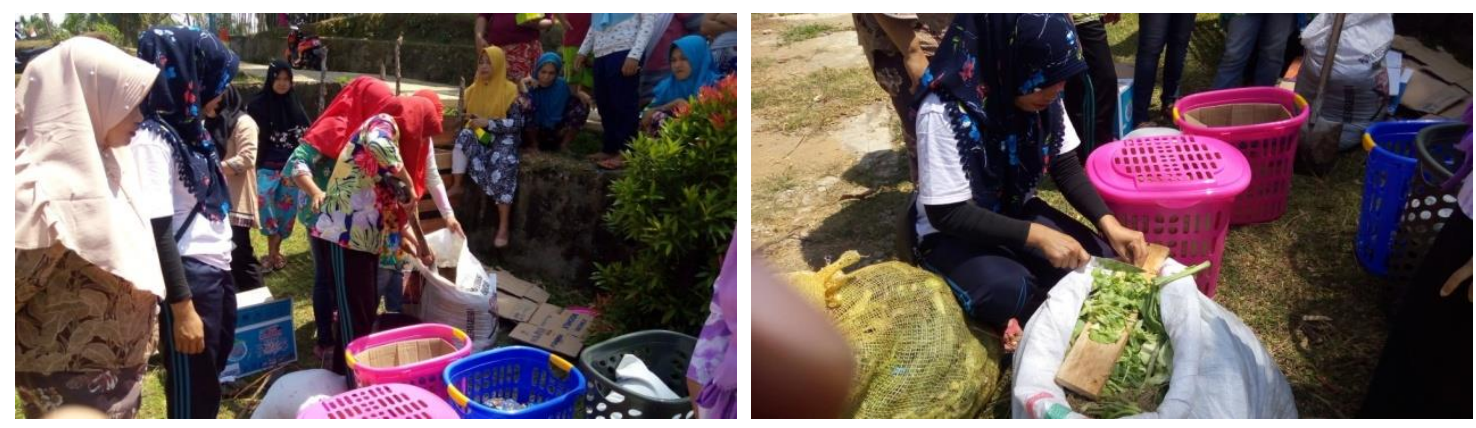

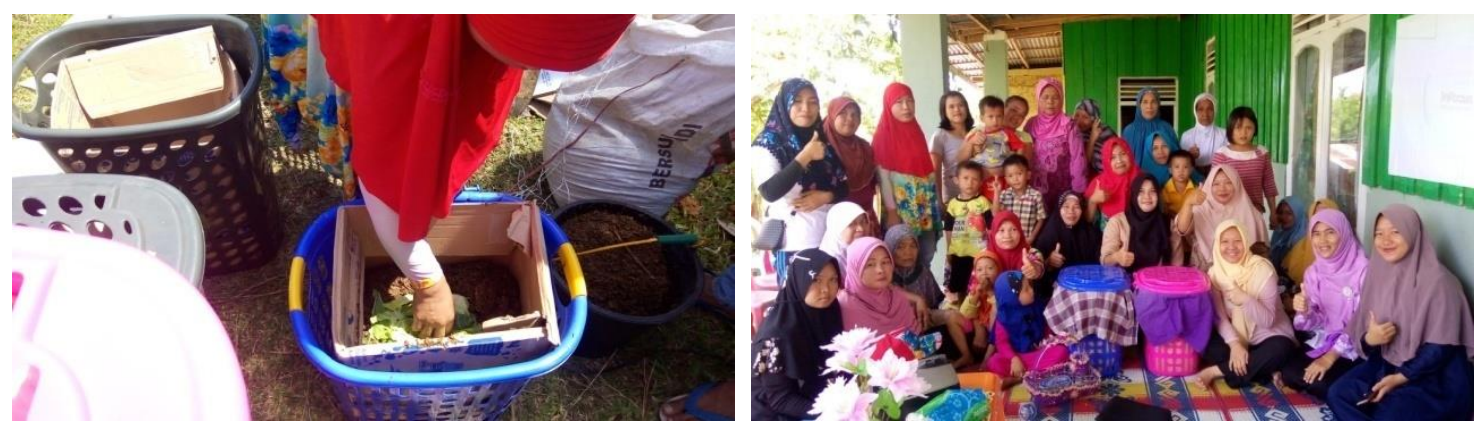

Gambar 4. Praktek pembuatan kompos Takakura

D. Monitoring dan evaluasi

Monitoring dan evaluasi dilaksanakan untuk melihat keberhasilan kegiatan. Kompos yang telah dibuat pada saat kegiatan, diisi sampah dan diinkubasi selama 1 bulan oleh masyarakat, diamati keberhasilannya. Hasil pengamatan menunjukkan kompos telah sedikit menyusut dan tekstur kompos menjadi lebih halus dari sebelumnya. Hal ini menunjukkan telah terjadi pematangan kompos. Seperti yang dinyatakan Murbandono (2007) bahwa pada proses pengomposan akan terjadi penyusutan volume maupun biomassa bahan hingga mencapai 30-40\% dari volume awal bahan.

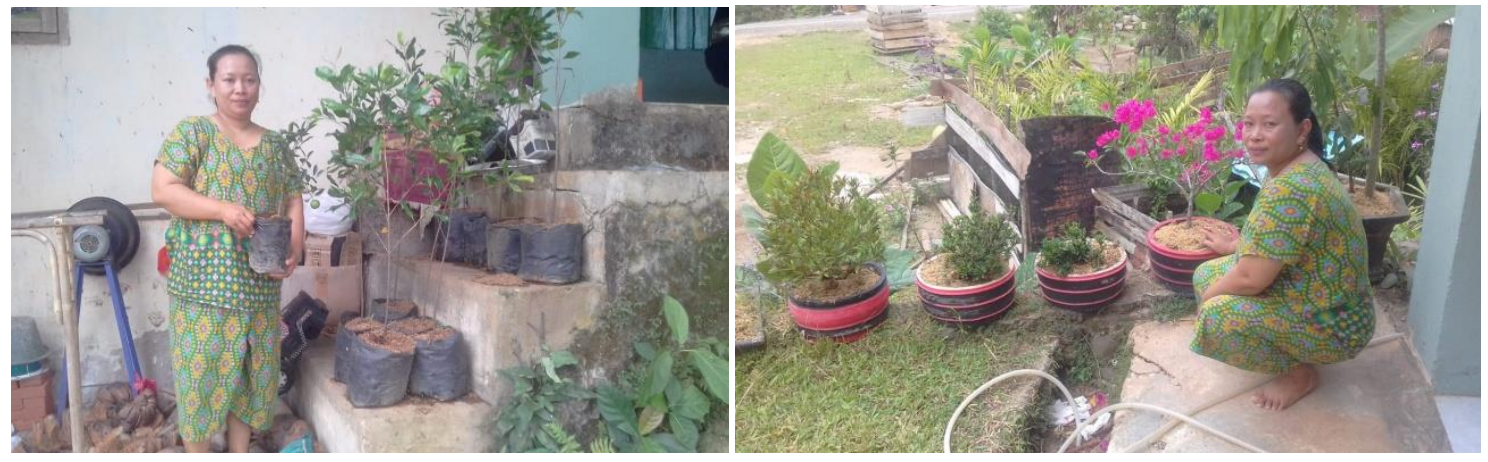

Gambar 5. Kompos Takakura yang dibuat telah jadi dan digunakan untuk penyubur tanaman oleh masyarakat

Kompos yang dihasilkan dari kegiatan ini sebagian dibiarkan di dalam komposter sebagai starter pembuatan kompos berikutnya, sedangkan sebagian lagi dikeluarkan dari komposter untuk digunakan sebagai pupuk (Gambar 5). Pemberian pupuk kompos sangat bermanfaat bagi tanaman dan tanah. Menurut Gaur (1980), pemberian kompos dapat menguntungan bagi tanah maupun tumbuhan, yaitu meningkatkan kesuburan tanah, memperbaiki struktur dan karakteristik tanah, meningkatkan kapasitas serap air tanah, meningkatkan aktivitas mikroba tanah, meningkatkan kualitas hasil panen, menyediakan hormon dan vitamin bagi tumbuhan, menekan pertumbuhan atau serangan penyakit tumbuhan, meningkatkan retensi dan ketersediaan hara di dalam tanah. 
Dharma Raflesia : Jurnal Ilmiah Pengembangan dan Penerapan IPTEKS

18 (1) 2020

\section{SIMPULAN DAN SARAN}

\section{Simpulan}

Kegiatan pengabdian pada masyarakat pelatihan teknologi kompos Takakura telah meningkatkan pengetahuan dan keterampilan masyarakat Desa Tanjung Terdana Kecamatan Pondok Kubang Bengkulu Tengah dalam pengelolaan sampah rumah tangga menggunakan teknologi sederhana pembuatan kompos Takakura.

\section{Saran}

Berdasarkan kegiatan yang telah dilakukan disarankan agar dalam pembuatan starter dapat menyesuaikan waktu dengan masa panen sehingga tidak kesulitan dalam memperoleh bahan (sekam).

\section{DAFTAR PUSTAKA}

Gaur, AC. (1983). A Manual of Rural Composting FAO. Rome : United Nation.

Murbandono, L., 2007. Membuat Kompos. Penebar Niaga Swadaya. Jakarta.

Rezagama, A., Samudro, G. 2015. Studi Optimasi Takakura dengan penambahan sekam dan bekatul. Jurnal Presipitasi $12(2): 66-70$.

Setyorini D., Saraswati R.,Anwar EA. (2006). Kompos. Pupuk Organik dan Pupuk Hayati. Editor: RDM Simanungkalit., Didi Ardi Suridikarta., Rasti Saraswati, Diah Setyorini dan Wiwik Hartatik. Balai Besar Litbang Sumberdaya Lahan Pertanian Badan Penelitian dan Pengembangan Pertanian.

Sumunar, D.R.S., Khotomah, N., Hadi, B.S. 2008. Pelatihan dan Sosialisasi Pengelolaan Sampah Rumah Tangga Berbasis Budaya Terhadap Guru Sekolah Dasar di Kecamatan Wirobrajan (Menuju Kota Jogja Green and Clean). Laporan Pengabdian pada Masyarakat. UNY.

Suriwiria HU., (2002). Pupuk Organik Kompos dari Sampah. Bioteknologi Agroindustri.Bandung : Humaniora Utama Press. 